\title{
Teaming up to make meaningful use of electronic health records
}

A s many a Canadian doctor has discovered, negotiating the circuitry of electronic health records can be a mind-numbing challenge.

Some, like Ottawa physician Dr. Heath Alsaffar, call it "a colossal headache" that often leaves doctors who take the electronic plunge mired in myriad issues of cost and connectivity (www.cmaj.ca/lookup/doi/10.1503/cmaj .109-3929 and www.cmaj.ca/lookup /doi/10.1503/cmaj.109-3930).

The situation is even more problematic for physicians in the United States, where regulators have made "meaningful use" of electronic health records a necessary condition to receive Medicare and Medicaid payments (www.cmaj.ca /lookup/doi/10.1503/cmaj.109-3361).

Faced with tight timetables to adopt electronic health information systems, several US doctors have banded together to create a website, Doctors Helping Doctors Transform Health Care, that aims to help physicians overcome the steep learning curve involved in adopting electronic platforms.

It's primarily a vehicle for physicians to share and obtain advice from colleagues who've already negotiated the perils of the process, says Janet Marchibroda, the website's executive director.

Among the greatest challenges most doctors face in moving to incorporate electronic technologies into their practice are changes in their workflow, and inevitably, cost, organizers say.

Even the basics of setting appointments runs differently simply because doctors "have more information at their fingertips," Marchibroda says. As well, financing the implementation and maintenance of the electronic technologies are often major obstacles.

Comprehending and implementing the government's meaningful use regulations is equally tricky, adds Dr. Peter Basch, a cofounder of Doctors Helping

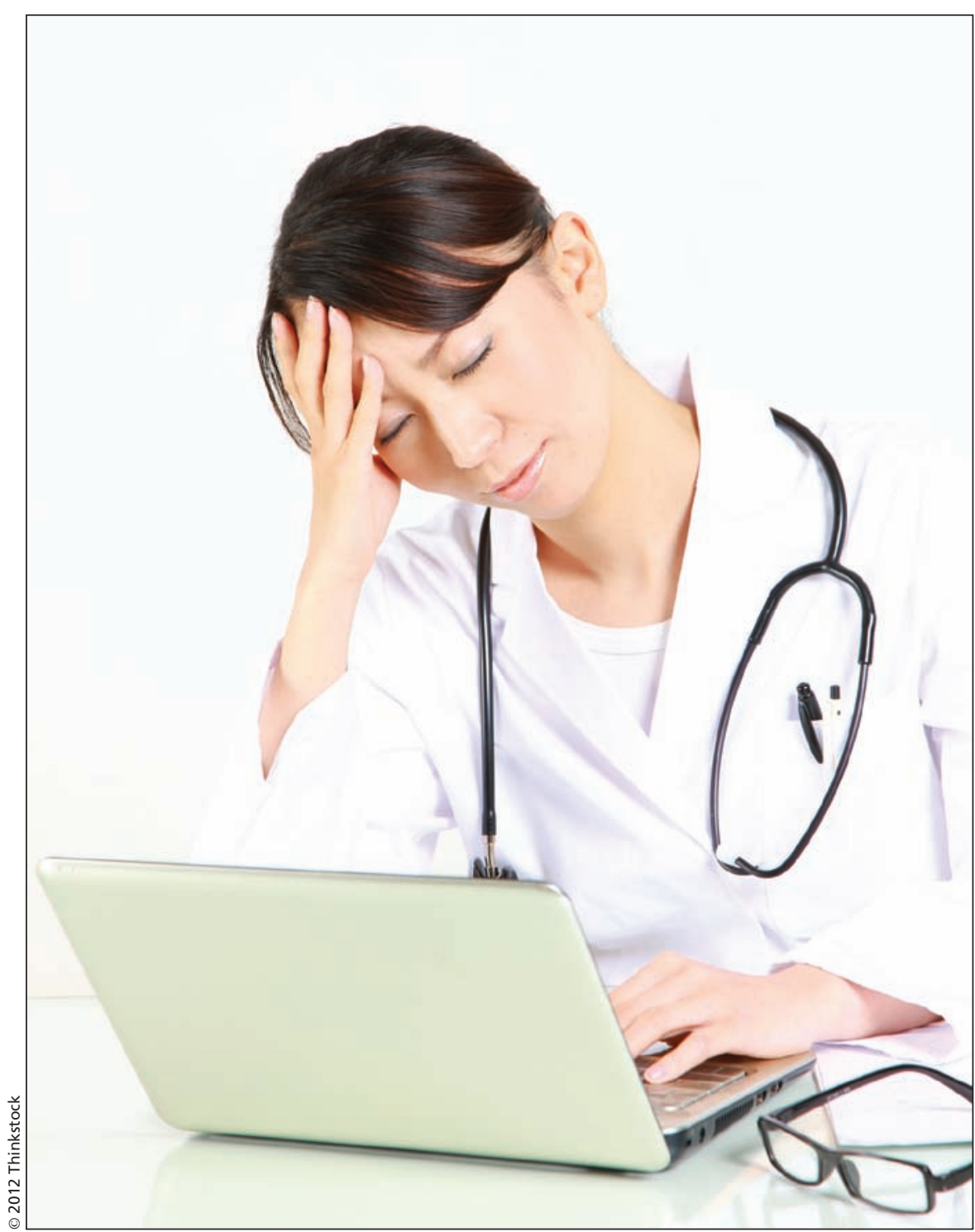

Financing the implementation and maintenance of the electronic technologies are among the obstacles in utilizing electronic health records.

Doctors Transform Health Care. The regulations require practicing professionals to meet 20 of 25 specified criteria, and hospitals to meet 19 of 24 criteria, to qualify for government payments for Medicare and Medicaid patients (www .cms.gov/EHRIncentivePrograms/30 _Meaningful_Use.asp\#TopOfPage).

It's resulted in a situation which "turned the focus from physicians act- ing as leaders and innovators in many ways to physicians being responders in a compliance exercise," Basch says.

Marchibroda notes that many doctors find the process discouraging as "implementation takes time away from seeing patients."

They need to be convinced that there are benefits to be reaped down the road, both in terms of savings to Amer- 
ica's health care system, and improved health care for patients, she adds.

Basch adds that it's important that physicians be actively involved in implementation of electronic health records. "Don't we want the people who are using these tools, who have a high level of trust with their patients, whose career is dedicated to doing the best things for their patients to help to be the people who are scripting the future of how health IT [information technology] is used?'

In linking doctors to provide each other advice on the implementation of electronic health records, organizers also say they have essentially developed the first physician-led social media initiative of its kind. "We saw a void and an opportunity to use the web as a social media tool to get into the nooks and crannies of the health care system," says Marchibroda.
It's an omen of initiatives to come as physicians find ever more useful and innovative ways to utilize the Internet in practice, says Nashua, New Hampshire-based primary care physician Dr. Kevin Pho, who is described as "social media's leading physician voice" at MedPage Today's www.KevinMD .com. "It can definitely be used as a vehicle where doctors can learn from each other, and sometimes patients can see these stories and realize some of the difficulties we face when we practice medicine, and doing it through stories is one of the most powerful ways to do so," he says.

Doctors can use social media to create an online presence, debate issues and connect with patients to dispel myths and interpret medical news, Pho adds.

A recent survey of 4000 US physi- cians found that $67 \%$ used social media for professional purposes (www .quantiamd.com/q-qcp/doctorspatient socialmedia.pdf). Other physician-only networking sites that have emerged include Sermo (www.sermo.com) and Doximity (www.doximity.com), which allows members to "connect with over 567000 US physician colleagues in 87 specialties."

But social media tools must be used with care, particularly with regard to potential breaches of patient privacy, Pho adds. "I think it's a matter of education. For the doctors using social media, it's still a relatively new phenomenon and I think we need to educate physicians on how to professionally use it and maintain their professionalism online." — Kayla Redstone, Ottawa, Ont.

CMAJ 2012. DOI:10.1503/cmaj.109-4090 